
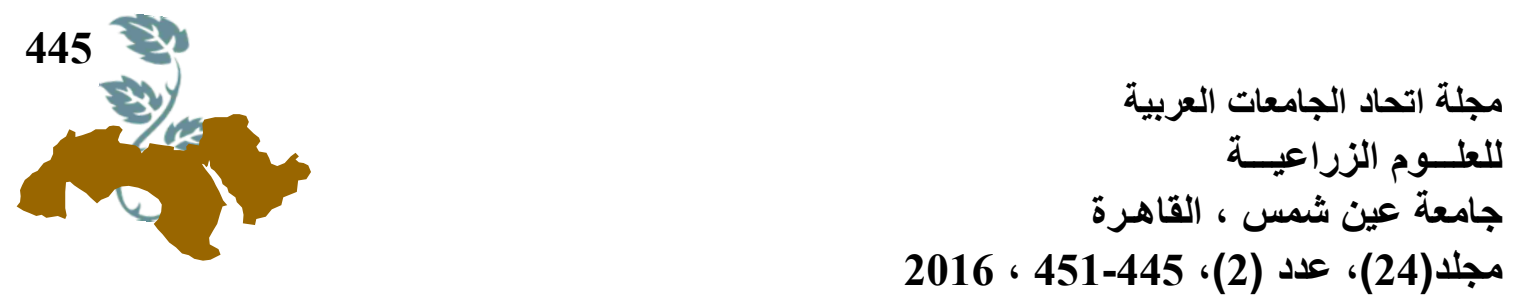

3تأثير استخام المعاملات البيولوجية لتحسين قابلية الهضم المعطي لتبن الرز

[30]

خالد دفيك احمد

$$
\text { مركز تتمية حوض اعالي الفرات - جامعة الانبار - العراق }
$$

المعاملة السابعة: مجموعة الخليط بين الانزيمات المحلة للألياف 0.4 غم والخميرة 0.4 غم مع 3 غم الانيعات من التبن

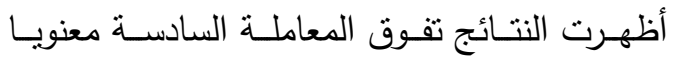
ف (P<0.05) على المعاملة الثالثة في كمية الغاز المنتج

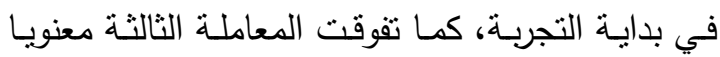

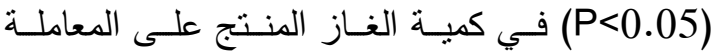

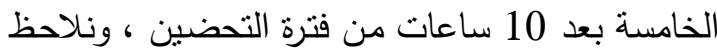

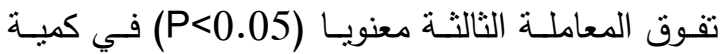

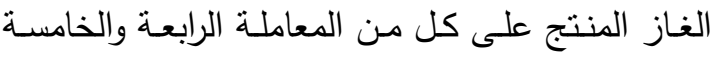

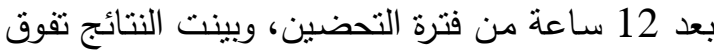
المعاملة الثانية والسادسة معنويا (P>0.05) في كمية

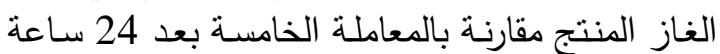

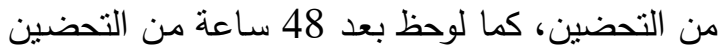

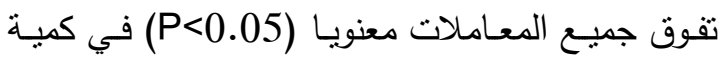

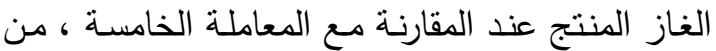
خلال التجربة نلاحظ تفوق المعاملة الخامسة والسادسة المانة في قيمـة الاس الهيدروجيني معنويـا (P>0.05) كل من المعاملة الثانية والرابعة ، و بينت الثيان النتائج وجود

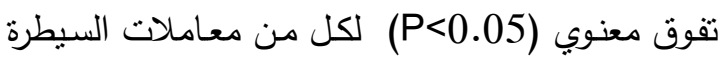

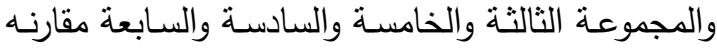

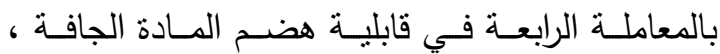
وتفوقت المعاملة الثالثة على المعاملـة السـابعة معنويـا

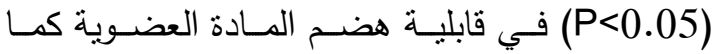
تفوقت المعاملة السادسة معنويا (P>0.05)
الكلمات الدالة: المعاملات البيولوجية، الهضم المعملي،

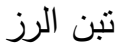

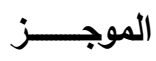

تهدف التجربة الى دراسة تأثير استخدام المعاملات

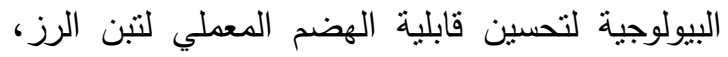

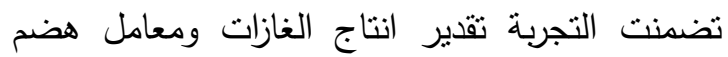
المادة الجافة ومعامل هضم المادة العضوية والاس الهيدروجيني pH، قسمت التجربة الى سبع معاملات: المعاملة الاولى: مجموعة السيطرة والتي احتوت على التى 3 غم من التبن فقط الاولي المعاملة الثانية: مجموعة الانزيمات المحلة للألياف 0.3 غم مع 3 غم من التبن. المعاملة الثالثة: مجموعة الانزيمات المحلة للألياف 0.4 غم مع 3 غم من التبن. المعاملة الرابعة: مجموعة الخميرة 0.3 غم مع 3 غم

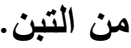
المعاملة الخامسة: مجموعة الخميرة 0.4 غم مع 3

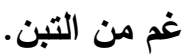
المعاملة السادسة: مجموعة الخليط بين الانزيمات

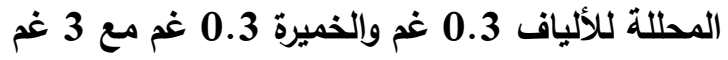

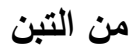

$$
\begin{aligned}
& \text { (تسليم البحث فى } 3 \text { مايو 2016) }
\end{aligned}
$$

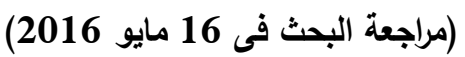

$$
\begin{aligned}
& \text { (الموافقة على البحث فى } 29 \text { مايو 2016) }
\end{aligned}
$$




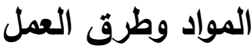

اجريت تجربة الهضم المختبري في مختبر التغذية التابع لقسم علم الحيوان في كلية الزراعة في جامعة فئة

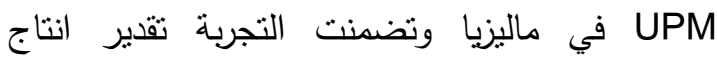
الغازات وقابلية هضم المادة الجافة والمادة العضوية

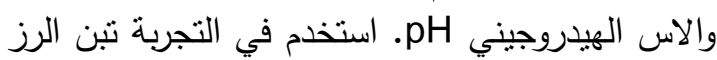
والإنزيمات الفطرية (إنتاج شركة Lesaffre الفرنسية والمستخلصة من فطر Trichoderma والاتيمات فتشمل ( cellulase, xylanase, B-glucanase إنزيمات وخميرة الخبز الحية (إنتاج شركة Lesaffre الفرنسية

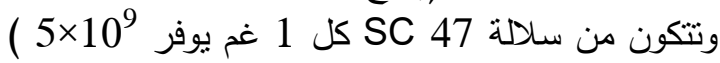
قسمت التجربة الى سبع معاملات: المعاملة الاولى: مجموعة السيطرة والتي احتوت على فئ فئل 3 غم من التبن فقط الاولي: المعاملة الثانية: مجموعة الانزيمات المحلة للألياف 0.3 غم مع 3 غم من التبن. المعاملة الثالثة: مجموعة الانزيمات المحلة للألياف 0.4 غم مع 3 غم من التبن. المعاملة الرابعة: مجموعة الخميرة 0.4 غم مع مع 3 غم

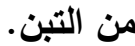

المعاملة الخامسة: مجموعة الخميرة 0.4 غم مع 3

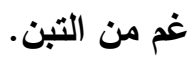
المعاملة السادسة: مجموعة الخليط بين الانزيمات المحلة للألياف 0.3 غم والخميرة 0.3 غم مع 3 غم الائم

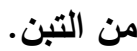
المعاملة السابعة: مجموعة الخليط بين الانزيمات المحلة للألياف 0.4 غم والخميرة 0.4 غم مع 3 غم التمانيم

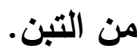

تم جمع عينات سائل الكرش بطريقة تبن من 3 كباش ناضجة قبل التغذية الصباحية بعدها

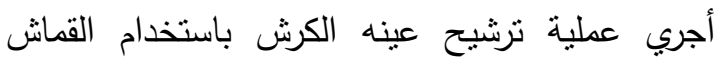

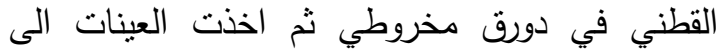
المختبر وتم حقن غاز CO2 الى عينه سائل الكرش

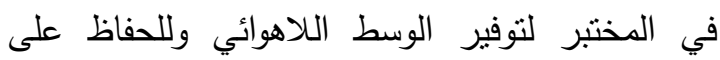
طبيعية محتويات العينة ، بعدها تم تحضير الوسط McDougall's وبعد اكمال عملية تحضير الوسط يمزج مع عينه سائل الكرش في بيكر كبير ينم اضافة 30 مل من المزيج
من المعاملة الثانية والرابعة و السابعة في قابلية هضم

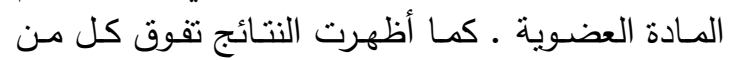

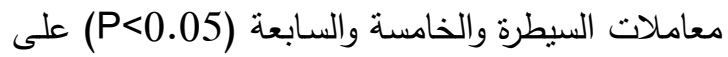

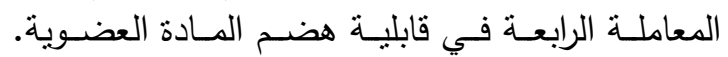

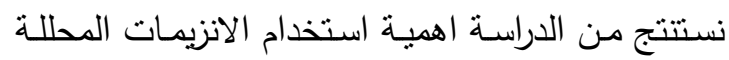

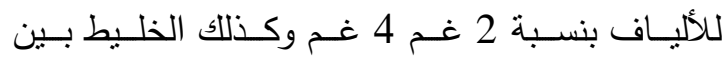

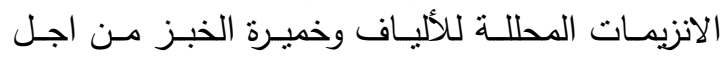
تحسين قابلية الهضم المعملي لتبن الرز .

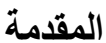

إن نقص الأعلاف الخشنة خصوصا الأعلاف الخضراء خلال موسم الجفاف والثتاء أدى إلى التوجها

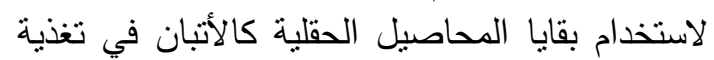

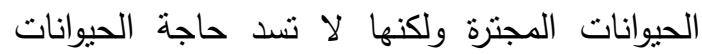

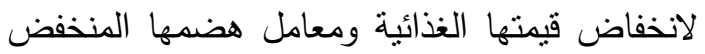
بسب ارتباط اللجنين مع السليلوز والهميسليلوز وعدم قدرة الإنزيمات الهاضمة التي تفرزها الإحياء المجهرية الهيلية

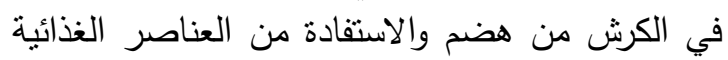

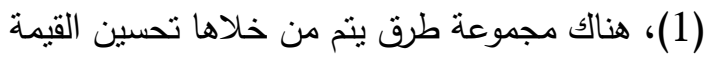
الغذائية للأعلاف المنخفضة النوعية منها المعاملات

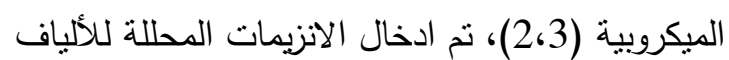

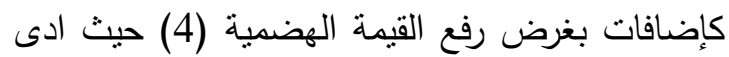

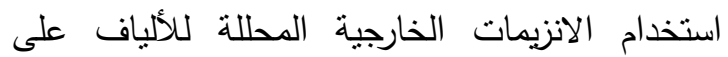

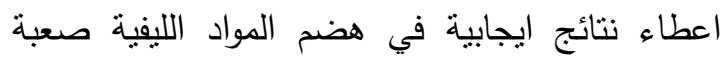

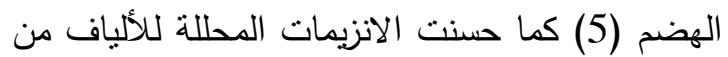

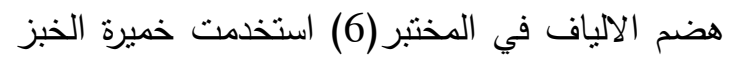
Saccharomyces Cerevisiae في علائق المجترات لتحسين هضم العناصر الغذائية

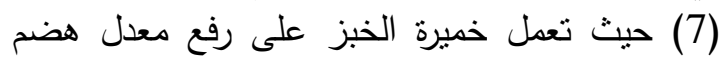

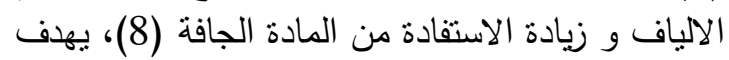

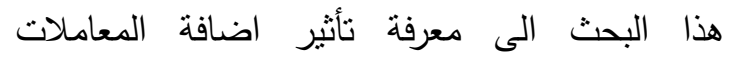
البيولوجية والتي تشمل كل من الانزيمات المحلة للألياف Fibrolytic enzymes الخبز Saccharomyces Cerevisiae على قابلية الهضم المعملي لتبن الرز وقياس معدل انتاج الغاز

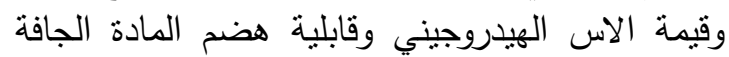
IVDMD والمادة العضوية IVMOD 
بالمعاملة الخامسة حيث بلغت كمية الغاز المنتج فيها

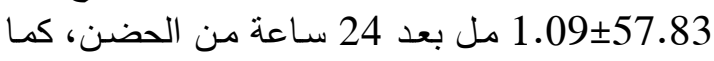

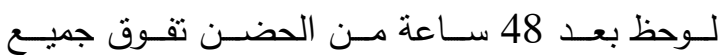

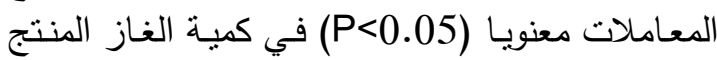

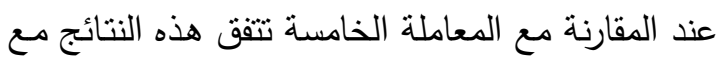

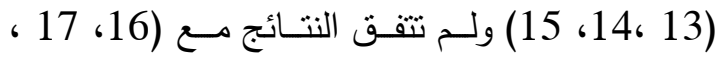

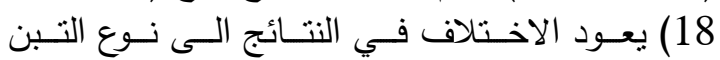

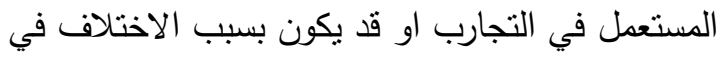

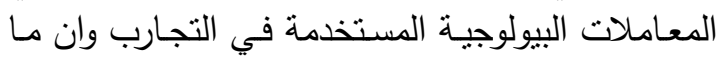

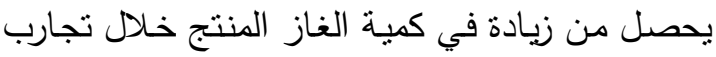

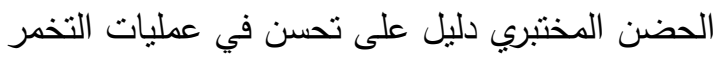

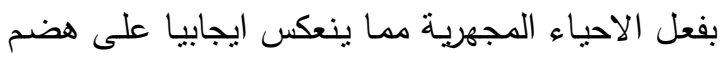
الالياف وزيـادة في انتاجيـة الاحمـاض الدهنية النيـة الطيارة . (20 ، 19)

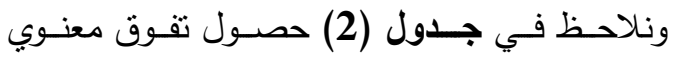

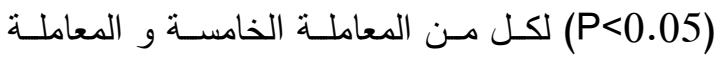

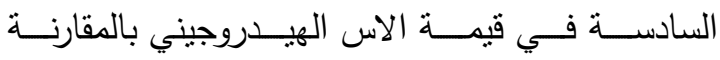

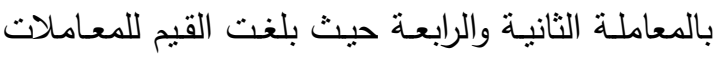

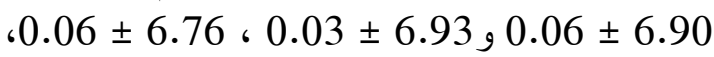

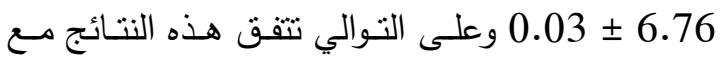

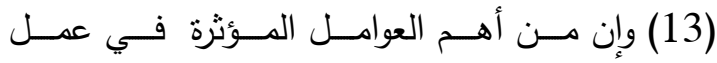

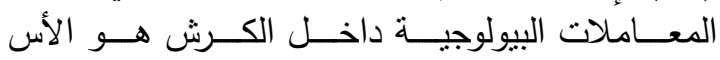

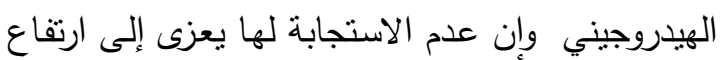

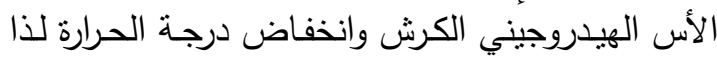

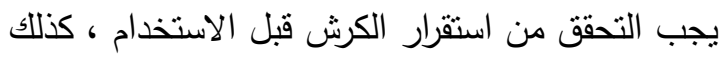

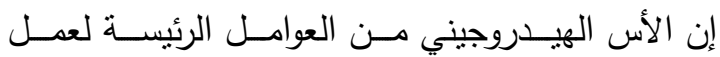

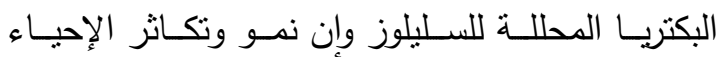
المجهرية يتأثران بقيمه الأس ألهيدروجيني لسائل الكرش الإن

وبينت النتائج في جدول (3) وجود تفوق معنوي

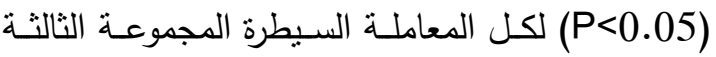

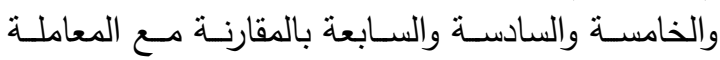

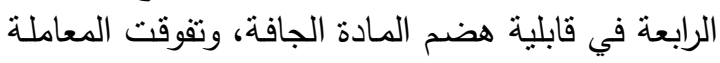

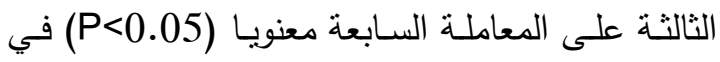

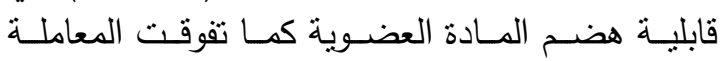

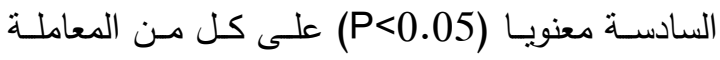

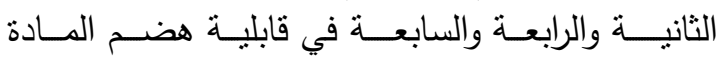

الى سرنجات زجاجية سعة 200 مل وتوضع في

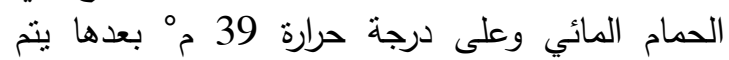

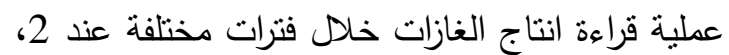

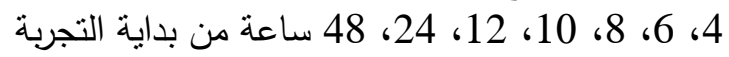
وحسب طريقة (9) بعد الانتهاء من القراءة تم تقريغ

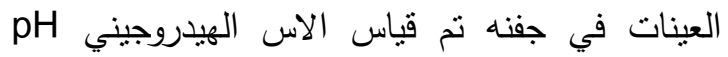

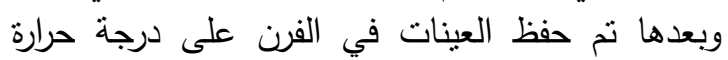

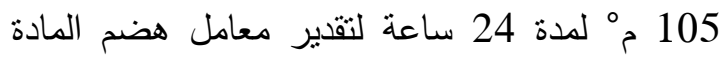
In Vitro dry matter (IVDMD) الجافة وبعدها حولت العينات الى فرن disappearance

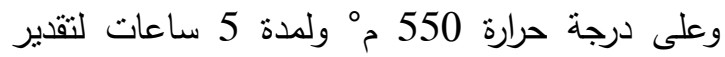

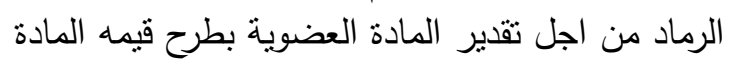

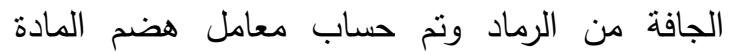
In Vitro organic matter (IVOMD) العضوية الجنة disappearance وحسب طريقة (10). أجري التحليل الإحصائي باستعمال برنامج

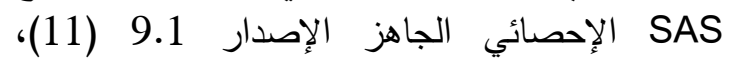
واختبرت الفروق المعنوية بين المتوسطات باستعمال اختبار Duncan (12) متعدد الحدود عند مستوى بندي معنوية 0.05 و 0.01 0.01

\section{النتائج وإلمناقشة}

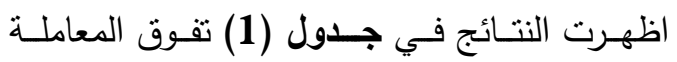

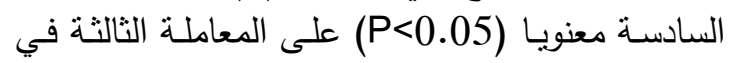

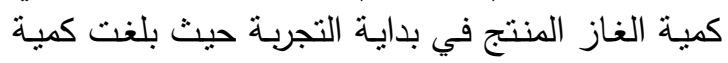

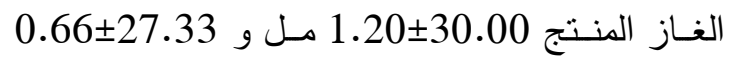
مل وعلى التوالي ، كما تفوقت المعاملة الثالثة معنويا

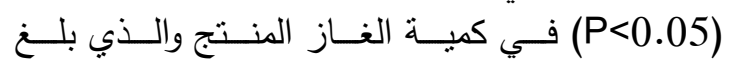

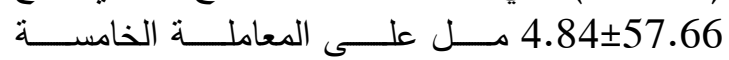

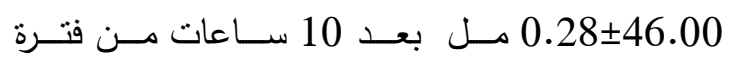

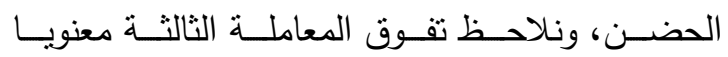
(P<0.05)

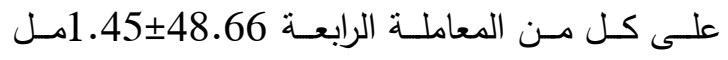

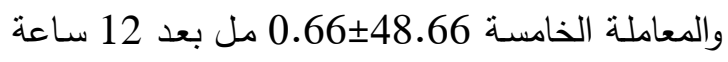
من فترة الحضن، وبينت النتائج تفوق المعاملـة الثانيـة

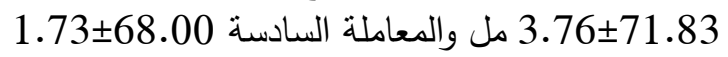
فـي كميــة الغـاز المنـتج معنويــا (P>0.05) مقارنــة 
جدول 1. تأثثر المعاملات البيولوجية على معدل انتاج الغازات

\begin{tabular}{|c|c|c|c|c|c|c|c|c|}
\hline مستوى & مجموعة الخليط بين & مجموعة الخليط بين & مجموعة خميرة & مجموعة خميرة & المحلة للالياف & مجموعة الانزيمات & مجموعة & النتاج \\
\hline 0.05 & $\begin{array}{c}0.33 \pm 28.66 \\
\text { ab }\end{array}$ & $\begin{array}{c}1.20 \pm 30.00 \\
\mathrm{a}\end{array}$ & $\begin{array}{c}0.66 \pm 28.33 \\
\text { ab }\end{array}$ & $\begin{array}{c}0.33 \pm 28.66 \\
\text { ab }\end{array}$ & $\begin{array}{c}0.66 \pm 27.33 \\
\text { b }\end{array}$ & $\begin{array}{c}0.88 \pm 28.66 \\
\text { ab }\end{array}$ & $\begin{array}{c}* 0.45 \pm 28.61 \\
\text { ab }\end{array}$ & باية \\
\hline 0.05 & $\begin{array}{c}0.88 \pm 35.66 \\
\text { b }\end{array}$ & $\begin{array}{c}1.20 \pm 35.66 \\
\text { b }\end{array}$ & $\begin{array}{c}0.33 \pm 34.66 \\
\text { b }\end{array}$ & $\begin{array}{c}0.33 \pm 34.33 \\
\text { b }\end{array}$ & $\begin{array}{c}1.85 \pm 36.66 \\
\mathrm{ab}\end{array}$ & $\begin{array}{c}1.15 \pm 36.00 \\
\text { b }\end{array}$ & $\begin{array}{c}0.51 \pm 34.89 \\
\text { b }\end{array}$ & سعد 2 \\
\hline 0.05 & $\begin{array}{c}1.01 \pm 39.83 \\
\text { b }\end{array}$ & $\begin{array}{c}1.85 \pm 39.33 \\
\text { b }\end{array}$ & $\begin{array}{c}0.16 \pm 38.16 \\
\text { b }\end{array}$ & $\begin{array}{c}0.50 \pm 37.50 \\
\text { b }\end{array}$ & $\begin{array}{c}2.66 \pm 42.33 \\
\text { ab }\end{array}$ & $\begin{array}{c}1.85 \pm 41.33 \\
\text { ab }\end{array}$ & $\begin{array}{c}0.76 \pm 37.67 \\
\text { b }\end{array}$ & 4 ساعة \\
\hline 0.05 & $\begin{array}{c}1.76 \pm 42.66 \\
\text { b }\end{array}$ & $\begin{array}{c}1.85 \pm 43.33 \\
\text { b }\end{array}$ & $\begin{array}{c}0.33 \pm 41.33 \\
\text { b }\end{array}$ & $\begin{array}{c}0.88 \pm 40.66 \\
\text { b }\end{array}$ & $\begin{array}{c}3.51 \pm 48.00 \\
\text { ab }\end{array}$ & $\begin{array}{c}2.02 \pm 45.66 \\
\text { ab }\end{array}$ & $\begin{array}{c}0.91 \pm 41.57 \\
\text { b }\end{array}$ & 6 ساعة \\
\hline 0.05 & $\begin{array}{c}2.29 \pm 45.50 \\
\text { b }\end{array}$ & $\begin{array}{c}2.51 \pm 47.00 \\
\text { b }\end{array}$ & $\begin{array}{c}0.28 \pm 43.50 \\
\text { b }\end{array}$ & $\begin{array}{c}1.45 \pm 44.33 \\
\text { b }\end{array}$ & $\begin{array}{c}4.50 \pm 53.00 \\
\text { ab }\end{array}$ & $\begin{array}{c}2.60 \pm 50.66 \\
\text { ab }\end{array}$ & $\begin{array}{c}1.10 \pm 44.67 \\
\text { b }\end{array}$ & 8 ساعة \\
\hline 0.05 & $\begin{array}{c}2.30 \pm 49.00 \\
\text { bc }\end{array}$ & $\begin{array}{c}1.66 \pm 50.66 \\
\text { bc }\end{array}$ & $\begin{array}{c}0.28 \pm 46.00 \\
\text { c } \\
\end{array}$ & $\begin{array}{c}1.87 \pm 46.83 \\
\text { bc }\end{array}$ & $\begin{array}{c}4.84 \pm 57.66 \\
\text { ab }\end{array}$ & $\begin{array}{c}3.28 \pm 55.33 \\
\text { abc }\end{array}$ & $\begin{array}{c}0.75 \pm 48.34 \\
\text { bc }\end{array}$ & 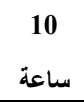 \\
\hline 0.05 & $\begin{array}{c}2.33 \pm 51.66 \\
\text { bc }\end{array}$ & $\begin{array}{c}1.66 \pm 53.66 \\
\text { bc } \\
\end{array}$ & $\begin{array}{c}0.66 \pm 48.66 \\
\text { c } \\
\end{array}$ & $\begin{array}{c}1.45 \pm 48.66 \\
\text { c } \\
\end{array}$ & $\begin{array}{c}5.00 \pm 61.00 \\
\text { ab } \\
\end{array}$ & $\begin{array}{c}2.84 \pm 57.66 \\
\text { abc } \\
\end{array}$ & $\begin{array}{c}0.89 \pm 51.34 \\
\text { bc } \\
\end{array}$ & 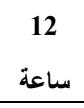 \\
\hline 0.05 & $\begin{array}{c}0.88 \pm 66.33 \\
\text { bc } \\
\end{array}$ & $\begin{array}{c}1.73 \pm 68.00 \\
\text { b } \\
\end{array}$ & $\begin{array}{c}1.09 \pm 57.83 \\
\text { c } \\
\end{array}$ & $\begin{array}{c}2.08 \pm 63.00 \\
\text { bc } \\
\end{array}$ & $\begin{array}{c}2.51 \pm 67.00 \\
\text { bc } \\
\end{array}$ & $\begin{array}{c}3.76 \pm 71.83 \\
\text { b } \\
\end{array}$ & $\begin{array}{c}1.99 \pm 62.00 \\
\text { bc } \\
\end{array}$ & 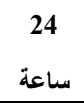 \\
\hline 0.05 & $\begin{array}{c}1.52 \pm 73.00 \\
\text { b }\end{array}$ & $\begin{array}{c}2.02 \pm 74.66 \\
\text { b }\end{array}$ & $\begin{array}{c}0.50 \pm 61.50 \\
\text { c }\end{array}$ & $\begin{array}{c}2.96 \pm 69.66 \\
b\end{array}$ & $\begin{array}{c}2.72 \pm 73.33 \\
\text { b }\end{array}$ & $\begin{array}{c}3.37 \pm 78.83 \\
\text { b }\end{array}$ & $\begin{array}{c}1.11 \pm 71.36 \\
\text { b }\end{array}$ & 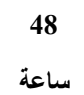 \\
\hline
\end{tabular}

"القيم تمثل المعدل 土 الخطأ القياسي.

P الحروف المختلفة ضمن الصف الواحد تشير إلى وجود فروق معنوية بين المعاملات عند مسنوى معنوية (a, b, b, c,d

جدول 2. تأثثر المعاملات البيولوجية على قيمة الاس الهيدروجيني

\begin{tabular}{|c|c|c|c|c|c|c|c|c|}
\hline مستوى & الانزيمات4 غم والخميرة الخيط بين & الانزيمات2غم والخميرة الخليط بين & مجموعة خميرة & مجموعة خميرة & المحللة للالياف & مجموعة الانزيمات & مجموعة & الصفات \\
\hline 0.05 & $\begin{array}{c}0.03 \pm 6.83 \\
\text { abcd }\end{array}$ & $\begin{array}{c}0.03 \pm 6.93 \\
\text { a }\end{array}$ & $\begin{array}{c}0.06 \pm 6.90 \\
a b\end{array}$ & $\begin{array}{c}0.03 \pm 6.76 \\
\mathrm{~cd}\end{array}$ & $\begin{array}{c}0.03 \pm 6.83 \\
\text { abcd }\end{array}$ & $\begin{array}{c}0.06 \pm 6.76 \\
\text { cd }\end{array}$ & $\begin{array}{c}\text { *0.02 } \pm 6.77 \\
\text { bcd }\end{array}$ & $\mathrm{pH}$ \\
\hline
\end{tabular}

*القيم تمثل المعدل 土 الخطأ القياسي.

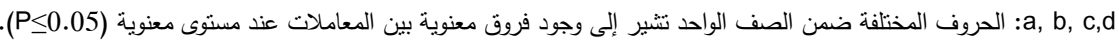




$$
\text { جدول 3. تأثير المعاملات البيولوجية على معامل هضم المادة الجافة والعضوية }
$$

\begin{tabular}{|c|c|c|c|c|c|c|c|c|}
\hline |المعنوية & | الانزيمات 4موعة الخليط بين & مجموعة الخليط & مجموعة خميرة & مجموعة خميرة & المحلة للالياف & | مجموعة الانزيمات & مجموعة السيطرة & الصفات \\
\hline 0.05 & $\begin{array}{c}0.15 \pm 77.52 \\
\text { bc }\end{array}$ & $\begin{array}{c}0.16 \pm 79.40 \\
\text { ab }\end{array}$ & $\begin{array}{c}0.56 \pm 78.35 \\
\text { abc }\end{array}$ & $\begin{array}{c}0.26 \pm 74.34 \\
\text { d }\end{array}$ & $\begin{array}{c}0.86 \pm 79.79 \\
\text { ab }\end{array}$ & $\begin{array}{c}1.72 \pm 76.54 \\
\text { cd }\end{array}$ & $\begin{array}{c}0.68 \pm 75.43 \\
\text { bc }\end{array}$ & IVDMD \\
\hline 0.05 & $\begin{array}{c}0.12 \pm 64.85 \\
\mathrm{~cd}\end{array}$ & $\begin{array}{c}0.12 \pm 67.21 \\
\text { ab }\end{array}$ & $\begin{array}{c}0.51 \pm 65.72 \\
\text { bcd }\end{array}$ & $\begin{array}{c}0.04 \pm 62.69 \\
\mathrm{e}\end{array}$ & $\begin{array}{c}0.77 \pm 67.25 \\
\text { ab }\end{array}$ & $\begin{array}{c}1.52 \pm 64.18 \\
\text { de }\end{array}$ & $\begin{array}{c}0.54 \pm 65.48 \\
\text { bcd }\end{array}$ & IVMOD \\
\hline
\end{tabular}

awassi lambs performance. Ph.D. Thesis University of Baghdad \College of Agriculture, Iraq.

Useni, B.A. 2011. Effect of exogenous fibrolytic enzymes on fibre and protein digestion in ruminant animals. MSc (Agric.) thesis, Stellenbosch University, Stellenbosch, South Africa.

Azzaz, H.H., Kholif, A.M., Murad, H.A., Hanfy, M.A. and Abdel Gawad, M.H. 2012. Utilization of cellulytic enzymes to improve the nutritive value of banana waste and performance of lactating goats. Asian J. Anim. and Vet. Advances. 7(8), $664-673$.

Rajamma K., Srinivas Kumar, D., Raghava Rao, E. and Narendra Nath, D.. 2015. In vitro evaluation of total mixed rations supplemented with or without fibrolytic enzymes. Anim. of Sci. Reporter, pp. 63-69.

Zabek, K., Milewski, S., Wojcik, R. and Siwicki, A.K. 2014. The effects of supplementing diets fed to pregnant and lactating ewes with Saccharomyces cerevisiae dried yeast. Turk. J. Vet. Anim. Sci. 38, 1621-1630.

Raj Kiran R., Srinivas Kumar, D. and Narendra Nath, D. 2014. Nutrient Utilization in buffalo bulls fed crop residue based complete rations supplemented with or withoutyeast culture. J. Adv. Vet Res., 4, 28-33.

Menke. Kil., R.aab, L., Salewski, A., Sreingass, H., Fritz, D. and Schneider, W. 1979. The estimation of the digestibility and inetabolizable energy content of ruminant feeding-stuffs from the gas production when they are incubated with ruinen liquor in vitro J. Agric. Sci. 93, 217222.
العضـوية. كمـا بينت النتائج تقوق كل مـن معـاملات السيطرة والخامسة والسابعة (P>0.05) على العيل المعاملة

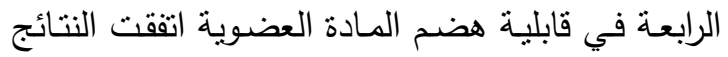

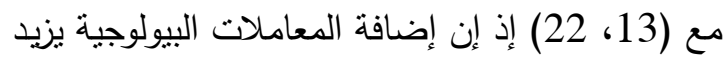

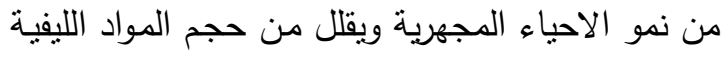

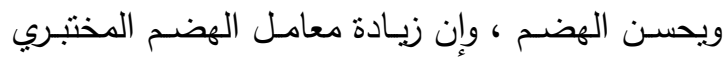

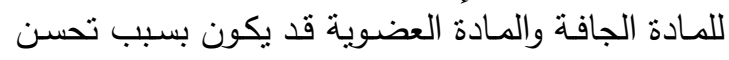
القيمة الغذائية للتبن بسبب تحرر السيليلوز نتيجة كسر لئر

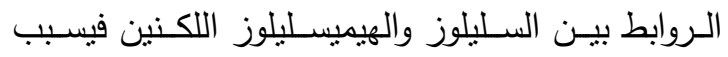

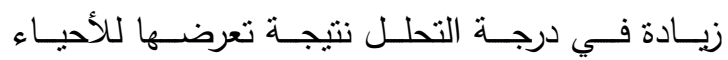
المجهرية وهذا يؤدي إلى زيادة الاستفادة من العناصر

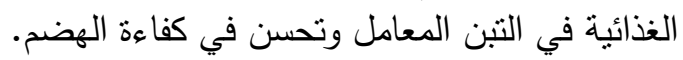

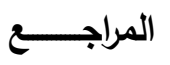

\section{المراجع الأنجليزية}

Van Soest, P.J. 1985. Definition of fiber in animal feeds. In: O. and B. Books Recent Advance in Animal Nutrition. PP. 55-70., Inc. Corvallis Oregon 97330.USA.

Beauchemin, K.A., Colombatto, D., Suksombat, W. and Phakachoed, N. 2013. Use of fibrolytic enzymes additives to enhance in vitro ruminal fermentation of corn silage. J. Livestock Science 157, 100-112.

Saeed, A. A.2011. Effect of level and degradability of dietary protein fed with or without bakers yeast ( saccharomyces cervisia ) to Turkish 
Tilley, J.M.A. and Terry, R.A. 1963. The relationship between the soluble constitutent herbage and their dry matter digestibility. J. British Feed Sci. 18, 104-111.

SAS, 2004. SAS User's guide: statistical system, Inc. Cary, NC. USA.

Duncan, D. 1955. Multiple range and multiple FTest. Biometrics. 11, 1-24.

Ahmed, K.D. 2015. Effect of adding Fibrolytic Enzymes and Yeast to the Diets on digestibility and Awassi lambs performance. Ph.D. Thesis. University of Anbar ICollege of Agriculture, Iraq.

Eun J.S., Beauchemin, K.A., Hong, S.H. and Bauer, M.W. 2006. Exogenous enzymes added to untreated or ammoniated rice straw: Effects on in vitro fermentation characteristics and degradability. Animal Feed Science and Technology.131, 86-101.

Tan, Z.L., Shah, M.A. and Murphy, M.R. 2004. Effects of dietary concentrate and forage ratio, energy and yeast culture supplementon in vitro dry matter degradability for lactating dairy cows. Acta Zoo/ nutrimenta 16, 26-32.

Liu, J.X., and Ørskov, E.R. 2000. Cellulase treatment of untreated and steam pre-treated rice straw-effect on in vitro fermentation characteristics. Anim. Feed Sci. Technol. 88, 189-200.

Ruiz, P.J.A., Moreno, A.J., Salem A.Z.M., Castelan Ortega O., Gonzalez-Ronquillo M. 2013. Chemical composition andin vitro gas production from different varieties of native and hybrid maize silage with the addition of acetic acid or enzymes. Animal Nutrition and Feed Technology 13, 593-599.

Eun, J.S. and Beauchemin, K.A. 2007. Assessment of the efficacy of varying experimental exogenous fibrolytic enzymes using in vitro fermentation characteristics. Anim. Feed Sci. Technol. 132, 298-315.

Colombatto, D., Mould, F.L., Bhat, M.K. and Owen, E. 2003. Use of fibrolytic enzymes to improve the nutritive value of ruminant diets. A biochemical and in vitro rumen degradation assessment. Anim. Feed Sci. Technol. 107, 201-209.

Wallace, R.J., Wallace, S.J., McKain, N., Nsereko, V.L. and Hartnell G.F. 2001. Influence of supplementary fibrolytic enzymes onthe fermentation of corn and grass silages by mixed ruminal microorganisms in vitro. J. of Anim. of Sci. 79, 1905-1916.

Ha, J.K., Emerick and Embry, L.B. 1983. In vitro effect of buffers in lambs before and after adaptation to high concentrate diets. J. Anim. of Sci. 56, 698-706.

Tang, S.X., Tayo, G.O., Tan, Z.L., Sun, Z.H., Shen, L.X., Zhou, C.S., Xiao, W.J., Ren, G.P., Han, X.F. and Shen, S.B. 2008. Effects of yeast culture and fibrolytic enzyme supplementation on invitro fermentation characteristics of low-quality cereal straws. J. of Anim. Sci., 86, 1164-1172. 